\title{
Statin rosuvastatin inhibits apoptosis of human coronary artery endothelial cells through upregulation of the JAK2/STAT3 signaling pathway
}

\author{
KUIJING WANG ${ }^{1}$, BO LI ${ }^{2}$, YUANYUAN XIE ${ }^{1}$, NAN XIA $^{3}$, MINGHUI LI $^{1}$ and GUANG GAO ${ }^{4}$ \\ ${ }^{1}$ Cadre Ward (Geriatric); Departments of ${ }^{2}$ Cardiology and ${ }^{3}$ Clinical Laboratory, The First Hospital of Harbin in Heilongjiang, \\ Harbin, Heilongjiang 150000; ${ }^{4}$ Department of General Surgery, AnZhen Hospital of Beijing, Beijing 100029, P.R. China
}

Received November 30, 2019; Accepted June 3, 2020

DOI: $10.3892 / \mathrm{mmr} .2020 .11266$

\begin{abstract}
The purpose of the present study was to explore the potential molecular signaling pathway mediated by the statin rosuvastatin in cultured human coronary artery endothelial cells (HCAECs) induced by $\mathrm{CoCl}_{2} \cdot \mathrm{CoCl}_{2}$ was used to induce the apoptosis of HCAECs. Myocardial infarction rats were established and received statin or PBS treatment. Reverse transcription-quantitative PCR, western blotting, ELISA, TUNEL assay and immunohistochemistry were used to analyze the role of statin treatment. The results showed that rosuvastatin treatment decreased apoptosis of HCAECs induced by $\mathrm{CoCl}_{2}$ by increasing anti-apoptosis $\mathrm{Bcl}-\mathrm{xl}$ and $\mathrm{Bcl}-2$ expression, and decreasing pro-apoptosis Bax, Bad, caspase-3 and caspase- 9 expression. The myocardial ischemia rat model demonstrated that rosuvastatin treatment decreased the mitochondrial reactive oxygen species, inflammation, mitochondrial damage, lipid catabolism, heart failure and the myocardial infarction areas, but improved the cardiac function indicators, right and left ventricular ejection fraction and increased expression levels of Janus kinase (JAK) and signal transducer and activator of transcription (STAT)3 in myocardial tissue. In conclusion, the results of the current study revealed that the statin rosuvastatin presents cardioprotective effects by activation of the JAK2/STAT3 signaling pathway.
\end{abstract}

\section{Introduction}

Complication of coronary heart disease (CAD) is a type of coronary artery atherosclerosis disease caused by myocardial ischemia $(1,2)$. CAD is also associated with inflammation and

Correspondence to: Professor Guang Gao, Department of General Surgery, AnZhen Hospital of Beijing, 2 Anzhen Road, Chaoyang, Beijing 100029, P.R. China

E-mail: anzhenmedicine@126.com

Key words: myocardial infarction, statin, rosuvastatin, apoptosis, human coronary artery endothelial cells, Janus kinase 2, signal transducer and activator of transcription 3 thrombosis, which leads to luminal stenosis or occlusion (3). Myocardial infarction is one type of CAD, caused by obstruction of the coronary artery lumen, which is induced by rupture of coronary artery atheromatous plaque and formation of thrombus $(4,5)$. Morbidity and the mortality rate of myocardial infarction are increasing worldwide $(2,6)$. A review of the current clinical evidence suggests that cardiovascular interventions can help myocardial infarction patients and reduce the high mortality rate (7). The body protects the heart against myocardial ischemia and reperfusion injury by modulating myocardial apoptosis and levels of inflammation $(8,9)$. Previous studies have also demonstrated that early apoptotic myocardial vascular aggravates the progression of myocardial infarction $(10,11)$.

Statins are hydroxymethyl glutaric acyl coenzyme A (HMG CoA) reductase inhibitors that can competitively inhibit the endogenous HMG CoA and block cell hydroxy valeric acid metabolic pathways, which further reduce cholesterol synthesis in the cell (12). A previous study found that statins cause secondary prevention in elderly patients following acute myocardial infarction (13). Chronic pre-treatment of statins is associated with the reduction of the no-reflow phenomenon in the patients with reperfused acute myocardial infarction (14). Statins demonstrate an early antiplatelet effect in patients with acute myocardial infarction, which results in a reduction in collagen-induced platelet aggregation (15). The effect of statins on long-term survival in patients hospitalized with acute myocardial infarction was investigated in 1,706 heart failure patients (16). These studies suggested that statins may be beneficial for the treatment of myocardial infarction.

Statins protect against arrhythmogenic calcium alternans in the post-myocardial infarction diabetic heart (17). Statins induce sirtuin 1 protein and have a cardioprotective role following premature myocardial infarction by impairment of endothelial nitric oxide synthase expression (18). In addition, rosuvastatin treatment was found to improve the efficacy of stem cell transplantation in infarcted hearts by activation of the Janus kinase (JAK) 2-signal transducer and activator of transcription (STAT)3 signaling pathway (19). Simvastatin treatment was found to ameliorate apoptosis of cardiomyocytes by reducing the expression of Bax and non-cleaved caspase- 3 and increasing STAT3 (20). In addition, atorvastatin was found 
to confer anti-inflammatory and anti-apoptotic effects under acute myocardial infarction settings which is hypothesized to ultimately contribute to cardiac function improvement (21). Therefore, concerns have been raised concerning statins due to their potential adverse impacts on myocardial infarction.

A previous study showed that $\mathrm{CoCl}_{2}$ induces hypoxic injury and mimics the hypoxia condition-induced injury in cardiomyocytes (22). In addition, apoptosis of coronary artery endothelial cells is a pro-atherogenic adhesion molecule central to initiation of atherosclerosis and progression towards plaque instability (23). Thus, the present study analyzed the anti-apoptotic effect of the statin rosuvastatin on human coronary artery endothelial cells (HCAECs). The present study used $\mathrm{CoCl}_{2}$ to mimic hypoxia condition-induced cardiomyocyte injury. The therapeutic effects of the statin rosuvastatin in myocardial infarction were examined and it was found that statin treatment significantly inhibited apoptosis of the HCAECs induced by $\mathrm{CoCl}_{2}$. It was also noted that rosuvastatin can protect the myocardium against myocardial infarction by regulation of the JAK2/STAT3 pathway.

\section{Materials and methods}

HCAEC culture. HCAECs were obtained from PromoCell $\mathrm{GmbH}$ and cultured in MEM medium (Sigma-Aldrich; Merck KGaA) containing 10\% fetal bovine serum (Sigma-Aldrich; Merck KGaA). $\mathrm{CoCl}_{2}$ (20 mM, Sigma-Aldrich; Merck KGaA) was used to induce hypoxic stimulation. The cells were grown in a humidified atmosphere containing $5 \% \mathrm{CO}_{2}$ at $37^{\circ} \mathrm{C}$. HCAECs were treated with the statin rosuvastatin $(0,1,2$ and $3 \mathrm{mg} / \mathrm{ml}$, Sigma-Aldrich; Merck KGaA) and/or JAK2 inhibitor AG490 ( $2 \mathrm{mg} / \mathrm{ml}$, Sigma-Aldrich; Merck KGaA) for further analysis.

Reverse transcription-quantitative (RT-q) PCR. Total RNA was extracted from human coronary artery endothelial cells $\left(1 \times 10^{7}\right)$ using RNAeasy Mini kit (Qiagen Sciences, Inc.). RNA was purified using the PureLink ${ }^{\mathrm{TM}}$ Pro 96 total RNA Purification Kit (Thermo Fisher Scientific, Inc.) and quantified using a Nanodrop 2000c UV-Vis Spectrophotometer (Thermo Fisher Scientific, Inc.) according to the manufacturer's instructions. Expression levels of Bcl-xl, Bcl-2, Bax and Bad in HCAEC were measured by RT-qPCR with $\beta$-actin as an endogenous control (24) (Invitrogen, Thermo Fisher Scientific, Inc.). The following thermocycling conditions were used for qPCR: Initial denaturation at $95^{\circ} \mathrm{C}$ for $300 \mathrm{sec} ; 45$ cycles of $95^{\circ} \mathrm{C}$ for $30 \mathrm{sec}, 57^{\circ} \mathrm{C}$ for $30 \mathrm{sec}$ and $72^{\circ} \mathrm{C}$ for $30 \mathrm{sec}$. All the forward and reverse primers were synthesized by Invitrogen (Thermo Fisher Scientific, Inc.) (Table I). Relative mRNA expression changes were calculated by the $2^{-\Delta \Delta \mathrm{Cq}}$ method (25). The results are expressed as $n$-fold change compared with $\beta$-actin.

Cell viability assay. Viability of endothelial cells was analyzed using the Cell Counting Kit-8 (CCK-8; Sigma-Aldrich; Merck $\mathrm{KGaA}$ ). Briefly, HCAEC at $1 \times 10^{5}$ cells/ml density were seeded into 6-well plates, $0.2 \% \mathrm{H}_{2} \mathrm{O}_{2}$ was added with or without rosuvastatin $(0,1.0,2.0$ and $3.0 \mathrm{mg} / \mathrm{ml})$ and then cultured for 24,48 and $72 \mathrm{~h}$ at $37^{\circ} \mathrm{C}$. A total of $10 \mu \mathrm{lCCK}-8$ solution was added to the cells and then the cells were cultured for $30 \mathrm{~min}$ at $37^{\circ} \mathrm{C}$. Cell viability was measured at $450 \mathrm{~nm}$ absorbance using a Microplate Reader (Bio-Rad Laboratories, Inc.).
Western blot analysis. HCAEC were homogenized in lysate buffer containing protease-inhibitor and were centrifuged at $6,000 \times \mathrm{g}$ at $4^{\circ} \mathrm{C}$ for $10 \mathrm{~min}$. The supernatant was used for analysis of the purpose protein. Total protein was quantified using a bicinchoninic acid assay kit (Thermo Fisher Scientific, Inc.). A total of $40 \mu \mathrm{g}$ protein/lane was separated via $15 \%$ SDS-PAGE and transferred onto nitrocellulose membranes, which were blocked with 5\% BSA (Sigma-Aldrich; Merck KGaA) at $4^{\circ} \mathrm{C}$ overnight. The primary antibodies used in the immunoblotting assays were: Bad (1:1,200, cat. no. ab32445, Abcam), Bax (1:1,200, cat. no. ab32503, Abcam), matrix metalloproteinase (MMP) 9 (1:1,200, cat. no. ab388981, Abcam), tumor necrosis factor (TNF) $\alpha(1: 1,200$, cat. no. ab6671, Abcam), NF- $\kappa$ B $(1: 1,200$, cat.no.ab220803, Abcam), interleukin(IL) 1 $\beta(1: 1,200$, cat. no. ab9722, Abcam), IL-10 (1:1,200, cat. no. ab9969, Abcam), peroxisome proliferator-activated receptor $\gamma$ coactivator (PGC) $1 \alpha$ (1:1,200, cat. no. ab54481, Abcam), brain natriuretic peptide (BNP; 1:1,200, cat. no. ab19645, Abcam), $\alpha$ myosin heavy chain (MHC; 1:1,200, cat. no. ab134189, Abcam), Bcl-xl (1:1,200, cat. no. ab32370, Abcam), Bcl-2 (1:1,200, cat. no. ab32124, Abcam), JAK2 (1:1,200, cat. no. ab108596, Abcam), phosphorylated (p-)JAK2 (1:1,200, cat. no. ab32101, Abcam), STAT3 (1:1,200, cat. no. ab68153, Abcam), p-STAT3 (1:1,200, cat. no. ab126459, Abcam) and $\beta$-actin $\left(1: 2,000\right.$, cat. no. ab8226, Abcam) for $12 \mathrm{~h}$ at $4^{\circ} \mathrm{C}$. The blots were then incubated with HRP-conjugated secondary antibody (1:5,000, cat. no. ab205718, Abcam) for $2 \mathrm{~h}$ at $37^{\circ} \mathrm{C}$ The bands of proteins were observed with an enhanced chemiluminescence substrate kit (cat. no. P0018F, Beyotime Institute of Biotechnology). Quantitative expression of proteins was quantified by ImageJ software (v4.6.2, National Institutes of Health).

TUNEL assay. To analyze the apoptosis of HCAECs in experimental rats following statin treatment $(10 \mathrm{mg} / \mathrm{kg} / \mathrm{day}$, Sigma-Aldrich; Merck KGaA) or the same dose of PBS, a TUNEL assay (Biotool Service $\mathrm{GmbH}$ ) was used to detect TUNEL-positive cells. The procedures were performed as in a previous study (26). Finally, hippocampal neuron cell images were captured with a ZEISS LSM 510 confocal microscope at $488 \mathrm{~nm}$.

Animals studies. Male SD rats (6-8-week, body weight, 200-220 g, $\mathrm{n}=40$ ) were purchased from the Chinese Academy of Sciences Institute of Biophysics. All rats were housed at $23-25^{\circ} \mathrm{C}$ with $50-60 \%$ humidity, 12-h light/dark cycles, and food and water ad libitum. Animal breeding and experiments were carried out under IACUC approved protocols at Provincial Hospital Affiliated to Shandong University. A myocardial infarction rat model was established by ligating the left anterior descending (LAD) coronary artery for $30 \mathrm{~min}$ followed by reperfusion for $4 \mathrm{~h}$ (27). Briefly, rats were anesthetized using pentobarbitone sodium $(50 \mathrm{mg} / \mathrm{kg})$. After disinfecting the surgical area, the left chest was opened to expose the heart. Rats were subjected to permanent LAD ligation using 6.0 prolene, approximately $2 \mathrm{~mm}$ in width and depth, in order to induce myocardial ischemia. Successful occlusion of the LAD was confirmed by observing the appearance of a paler color below the ligation area and ST-segment elevation on ECG (PowerLab System, AD Instruments Ltd.) 
Table I. Primers for reverse transcription-quantitative PCR.

Sequence

\begin{tabular}{lll}
\cline { 2 - 3 } Gene name & \multicolumn{1}{c}{ Reverse } & \multicolumn{1}{c}{ Forward } \\
\hline Bax & 5'-CTTCTCACTGTCGACTACCGC-3' & 5'-GCGTCTCCTGTGCATTCG-3' \\
Bcl-2 & 5'-GCAAGGACAAGATTCGATACT-3' & 5'-GCCAGACTACATGGAAATCTA-3' \\
Bcl- $x l$ & 5'-CATGCTGGGGCCGTACAG-3' & 5'-TTGTCCGACCTTTGGCAACT-3' \\
Caspase-3 & 5'-ATTTGCGTGTGGAGTATTTGG-3' & 5'-GCTGTTCCGTCCCAGTAGATTA-3' \\
Caspase-9 & 5'-AGCAATAAATGAATGGGCTGAG-3' & 5'-GTATGGAGAAATGGGCTGTAGG-3' \\
$\beta$-actin & 5'-CATTTCATGGTGGAGGTGAAG-3' & 5'-GGGAACTGCAGGTGGCTG-3' \\
\hline
\end{tabular}

were used to confirm a successful occlusion of the LAD coronary artery. Myocardial infarction rats were divided into two groups ( $\mathrm{n}=20$ in each group) and received rosuvastatin ( $1 \mathrm{mg} / \mathrm{kg}$, Sigma-Aldrich; Merck KGaA) or the same PBS dose in a total of 60-day treatment once a day. At the end of experimental period, rats were euthanized by cervical dislocation under pentobarbital (50 mg/kg i.p.) anesthesia.

Blood biochemical parameters. Blood samples $(0.5 \mathrm{ml})$ in vena caudalis were collected from experimental rats at the end of experiments and immediately transferred to the Central Laboratory. Serum was obtained using centrifugation $\left(12,000 \times \mathrm{x}, 10 \mathrm{~min}, 4^{\circ} \mathrm{C}\right)$ and used to determine concentrations of serum low-density lipoprotein cholesterol (LDL-c), hypersensitive C-reactive protein (hSCRP; reference value: $0-5 \mathrm{mg} / \mathrm{l})$, leucocytes (WBC), neutrophil counts (\%) and mean platelet volume (MPV). Left ventricular ejection fraction (LVEF) and left ventricular fractional shortening (LVFS) were measured as described previously (28).

Measurement of the myocardial infarct size. At the end of treatment, the hearts from the two groups were immediately placed in a $-80^{\circ} \mathrm{C}$ freezer for $10 \mathrm{~min}$ and cut into $2-3 \mathrm{~mm}$ thick slices along the sagittal plane of the heart. Myocardial tissues were stained in 2,3,5-triphenyl-2H-tetrazolium chloride (TTC) solution $\left(37^{\circ} \mathrm{C}, 1 \% \mathrm{TTC}, \mathrm{pH} 7.4\right)$ for $30 \mathrm{~min}$. Subsequently, myocardial tissues were incubated with $10 \%$ formaldehyde solution for fixation for $24 \mathrm{~h}$ at $4^{\circ} \mathrm{C}$. The infarct area in the myocardial tissues was analyzed with ImageJ (v4.6.2, National Institutes of Health) and images were captured with a digital camera.

Determination of mitochondrial reactive oxygen species (ROS) generation. Mitochondrial ROS production rate was detected using fluorometric methods (29). In brief, $2.9 \mathrm{ml}$ of mitochondrial ROS assay medium and $3 \mathrm{ml}$ of $5 \mathrm{mmol} / \mathrm{l}$ $2^{\prime}, 7^{\prime}$-dichlorofluorescin diacetate were incubated at $37^{\circ} \mathrm{C}$ for $15 \mathrm{~min}$ and the fluorescence intensity of the reaction system with mitochondria was measured using the fluorescence intensity of the reaction system without mitochondria. The ROS generation rate was calculated by subtracting the basal fluorescence intensity from the sample florescence intensity.

Immunological staining. The effects of rosuvastatin treatment on neuronal loss were evaluated using immunohistochemical staining of myocardial tissue from experimental rats. Staining was performed on myocardial tissues in animals following treatment by statin or PBS only. Immunohistochemical procedures were previously reported in detail (30). Free-floating sections were rinsed and placed in the solution with the rabbit anti-rat primary antibody of Bad (1:1,200, cat. no. ab32445, Abcam), Bax (1:1,200, cat. no. ab32503, Abcam), JAK2 $(1: 1,200$, cat. no. ab108596, Abcam) and STAT3 $(1: 1,200$, cat. no. ab68153, Abcam). After rinsing, sections were incubated in the presence of horseradish peroxidase-conjugated anti-rabbit IgG antibodies (1:5,000; cat. no. ab6721; Abcam) for $24 \mathrm{~h}$ at $4^{\circ} \mathrm{C}$. The results were visualized by using a chemiluminescence detection system (Cytiva).

Statistical analysis. All data are expressed as mean \pm standard deviation of triplicate dependent experiments and analyzed by using Student's t-tests or one-way ANOVA followed by Tukey's HSD test. All data were analyzed using SPSS Statistics 19.0 (IBM Corp.) and GraphPad Prism version 5.0 (GraphPad Software, Inc.) with Microsoft Excel (version 2010; Microsoft Corporation). $\mathrm{P}<0.05$ was considered to indicate a statistically significant difference.

\section{Results}

Statin rosuvastatin increases survival of HCAECs treated by $\mathrm{CoCl}_{2}$. The effect of rosuvastatin on the survival of HCAEC apoptosis induced by $\mathrm{CoCl}_{2}$ was analyzed in the present study. As shown in Fig. $1 \mathrm{~A}$ and $\mathrm{B}, \mathrm{CoCl}_{2}$ decreased the viability of the sHCAEC in a dose- and time-dependent manner. Viability of the HCAECs was increased in the statin-treated $\left(\mathrm{CoCl}_{2}+\right.$ statin) group compared with $\mathrm{CoCl}_{2}$-treated group (Fig. 1C). Data demonstrated that $2 \mathrm{mg} / \mathrm{ml}$ of statin presented the optimal efficacy in increasing the viability of the HCAECs. As depicted in Fig. 1D, $2 \mathrm{mg} / \mathrm{ml}$ of statin increased viability of the HCAECs in a time-dependent manner. These results indicate that statin is beneficial for myocardial infarction by reversing the $\mathrm{CoCl}_{2}$-reduced viability of HCAECs.

Statin rosuvastatin inhibits apoptosis of HCAECs induced by $\mathrm{CoCl}_{2}$. Apoptosis of HCAECs plays an important role in the progression of myocardial infarction. The present study showed that rosuvastatin inhibited apoptosis of HCAECs induced by $\mathrm{CoCl}_{2}$ (Fig. 2A). Results demonstrated that 
A
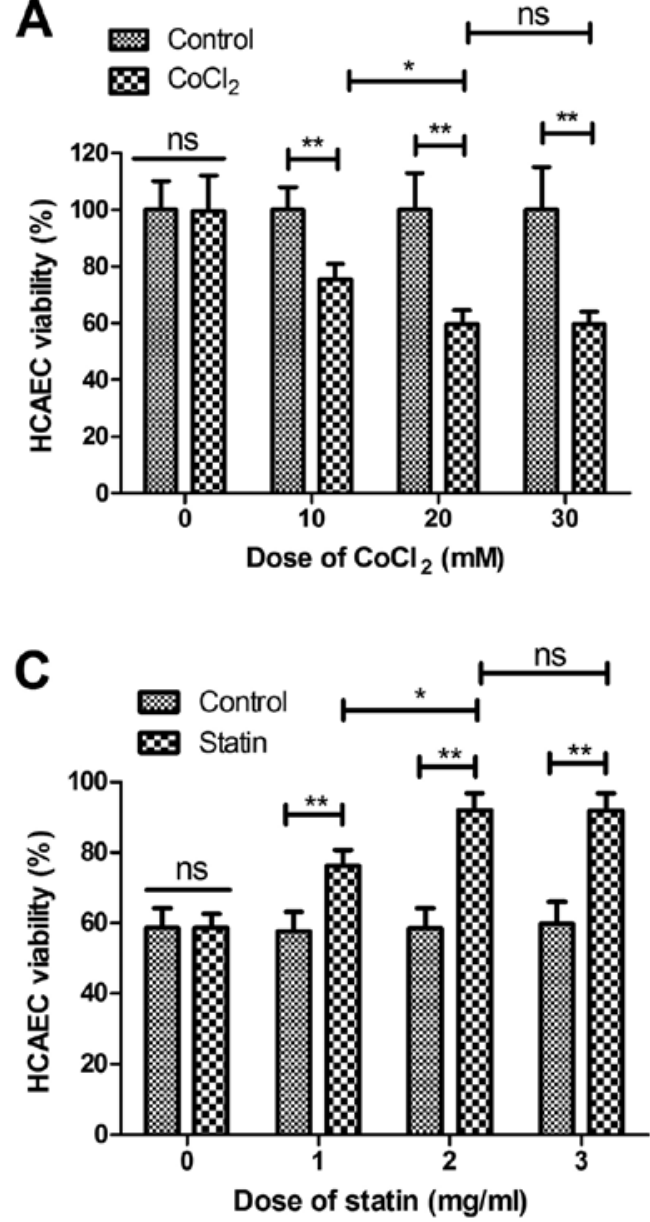

B $\quad$ Control
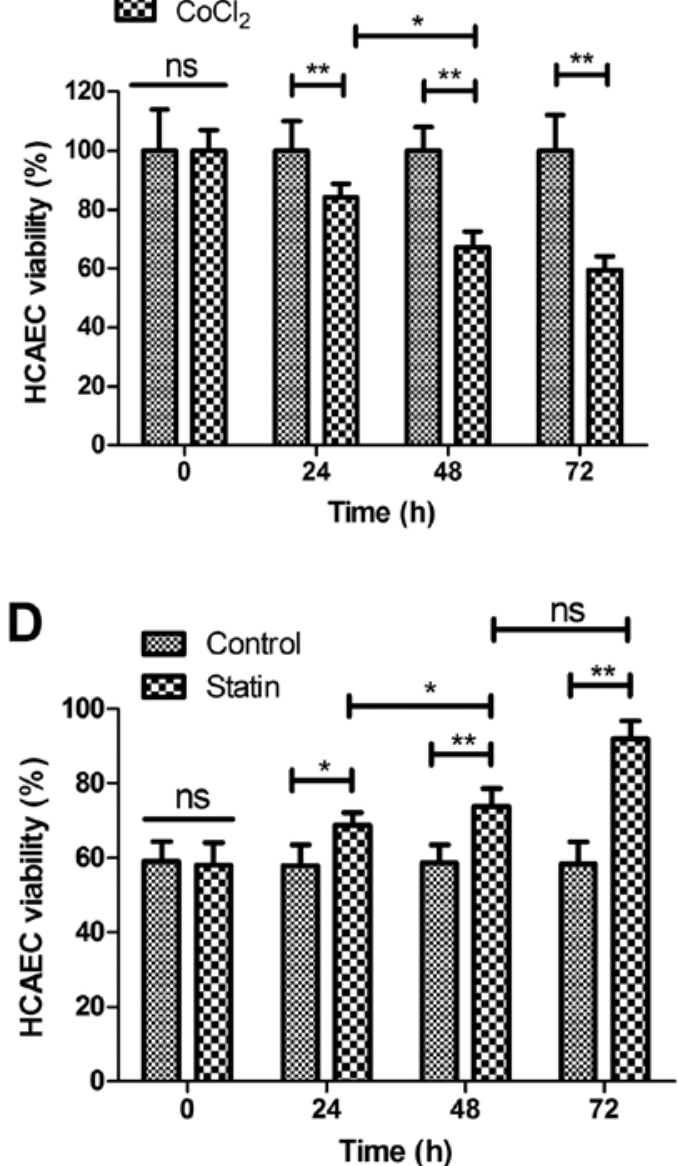

Figure 1. Statin rosuvastatin increases the viability of HCAECs induced by $\mathrm{CoCl}_{2}$. (A) $\mathrm{CoCl}_{2}$ decreased viability of $\mathrm{HCAECs}$ in a dose-dependent manner $(0,10,20$ and $30 \mathrm{mM})$ compared with the non-treated group. (B) $\mathrm{CoCl} 2$ decreased viability of HCAECs in a time-dependent manner (24, 48 and 72 h) compared with the non-treated group. (C) Rosuvastatin increased the viability of HCAECs in dose-dependent manner (0, 1.0, 2.0 and 3.0 mg/ml) compared with the non-treated group. (D) Statin increased viability of HCAECs in a time-dependent manner $(24,48$ and $72 \mathrm{~h})$ compared with non-treated group. ${ }^{*}<0.05$, ${ }^{* *} \mathrm{P}<0.01$; ns, not significant; HCAECs, human coronary artery endothelial cells.

rosuvastatin treatment increased anti-apoptosis Bcl-xl and Bcl-2 protein and mRNA expression (Fig. 2B and C), while pro-apoptosis Bax and Bad mRNA and protein expression was decreased by statin treatment (Fig. 2D and E). Statin treatment also decreased the apoptotic markers caspase-3 and caspase- 9 mRNA and protein in HCAECs compared with the control (Fig. 2F and G). These results indicated that statin treatment inhibits the apoptosis of HCAECs induced by $\mathrm{CoCl}_{2}$.

Statin rosuvastatin suppresses apoptosis of HCAECs through regulation of the JAK2/STAT3 pathway. The potential mechanism mediated by rosuvastatin was investigated in HCAECs induced by $\mathrm{CoCl}_{2}$. Statin treatment significantly increased JAK2, p-JAK2, STAT3 and p-STAT3 expression in the HCAECs (Fig. 3A). Results showed that the JAK2 selective inhibitor AG490 decreased and abolished statin-promoted JAK2 and STAT3 expression in the HCAECs. In addition, statin-inhibited apoptosis of HCAECs was abolished by JAK2 inhibitor AG490 (Fig. 3B). Apoptosis-regulated protein expression levels were also reversed by JAK2 inhibitor AG490 in statin-regulated HCAECs (Fig. 3C and D). Results also showed that JAK2 inhibitor AG490 abolished statin-regulated
Bcl-2, Bcl-xl, Bad and Bax levels in the HCAECs induced by $\mathrm{CoCl}_{2}$ (Fig. 3E). These results indicate that statin can significantly suppress apoptosis of HCAECs through regulation of the JAK2/STAT3 pathway.

Impact of statin treatment on inflammatory markers and cellular parameters in myocardial infarction rats. The effects of rosuvastatin treatment on inflammatory markers and cellular parameters were further analyzed in myocardial infarction rats. Results showed that statin treatment reduced hsCRP, white blood cell (WBC) and LDL-c levels, but increased neutrophils, MPV, LVEF and LVFS compared with the control (Fig. 4A-E). These results indicated that statin could decrease inflammatory markers in myocardial infarction rats.

Expression of inflammatory, mitochondrial damaged and cardiac hypertrophic failure in myocardial infarction rats. As shown in Fig. 5A, protein levels of MMP-9, TNF- $\alpha$, NF- $\kappa$ B and IL-1 $\beta$ were decreased by rosuvastatin compared with the control. Anti-inflammatory cytokine IL-10 was increased by treatment with rosuvastatin (Fig. 5B). An indicator of mitochondrial damage and mitochondrial integrity, cytosolic cytochrome $c$, was decreased by statin (Fig. 5C). A major 
A

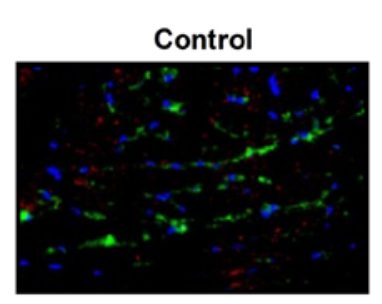

B

Control

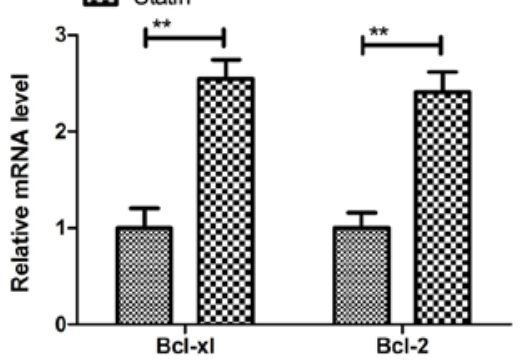

D

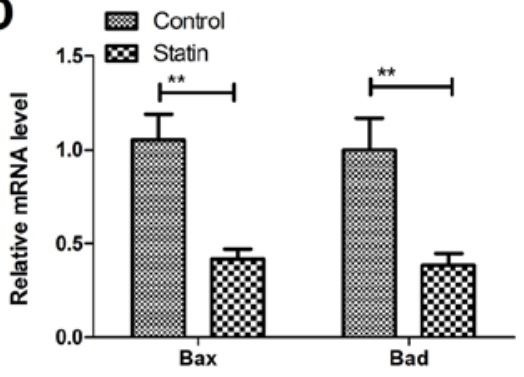

Statin

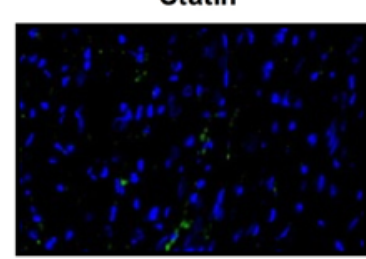

C
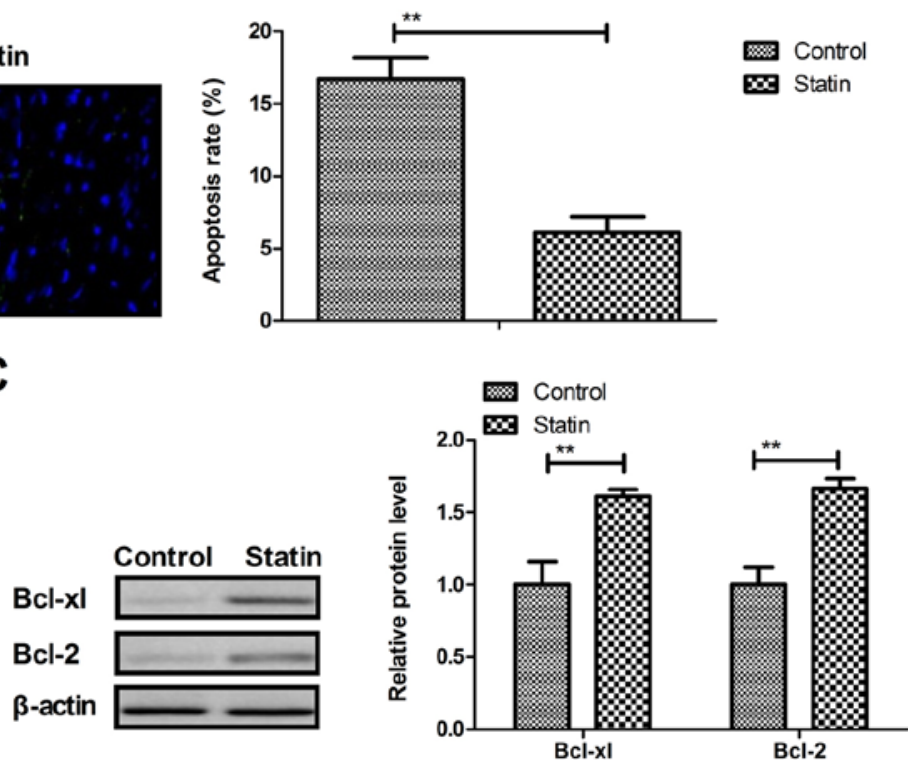

E

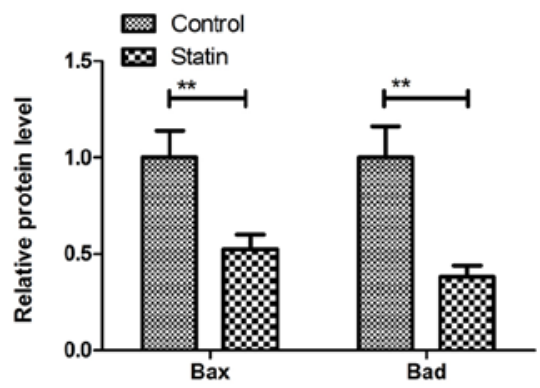

$\mathbf{F}$
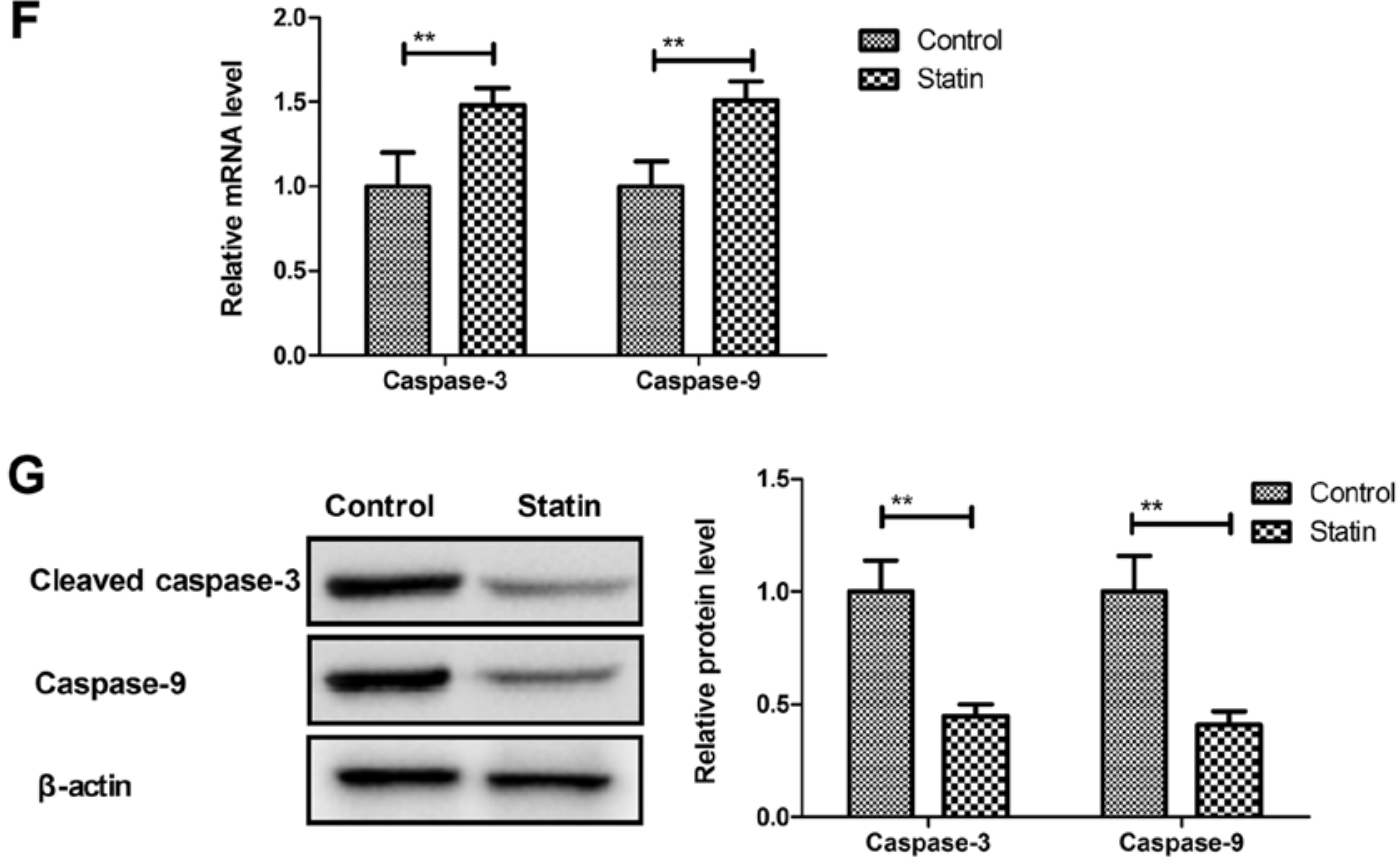

Figure 2. Statin rosuvastatin inhibits apoptosis of $\mathrm{HCAECs}$ induced by $\mathrm{CoCl}_{2}$. (A) Statin inhibited apoptosis of $\mathrm{HCAECs}$ induced by $\mathrm{CoCl}$ (magnification, $\mathrm{x} 50$ ). (B and C) Statin treatment increased anti-apoptosis Bcl-xl and Bcl-2 mRNA (B) and protein (C) expression in the HCAECs. (D and E) Statin treatment decreased Bax and Bad mRNA (D) and protein (E) in the HCAECs. (F and G) Statin treatment decreased apoptotic markers caspase-3 and caspase-9 mRNA (F) and protein $(\mathrm{G})$ in the HCAECs. ${ }^{* *} \mathrm{P}<0.01$, compared to the Control group. HCAECs, human coronary artery endothelial cells.

upstream regulator of lipid catabolism PGC-1 $\alpha$, indicator of heart failure BNP and $\alpha-\mathrm{MHC}$ were increased by statin in the myocardial infarction rats (Fig. 5D). These data indicated that statin treatment presented benefits in improvement of inflammation, mitochondrial damage and cardiac hypertrophic failure. 
A Control AG490-Statin Statin AG490
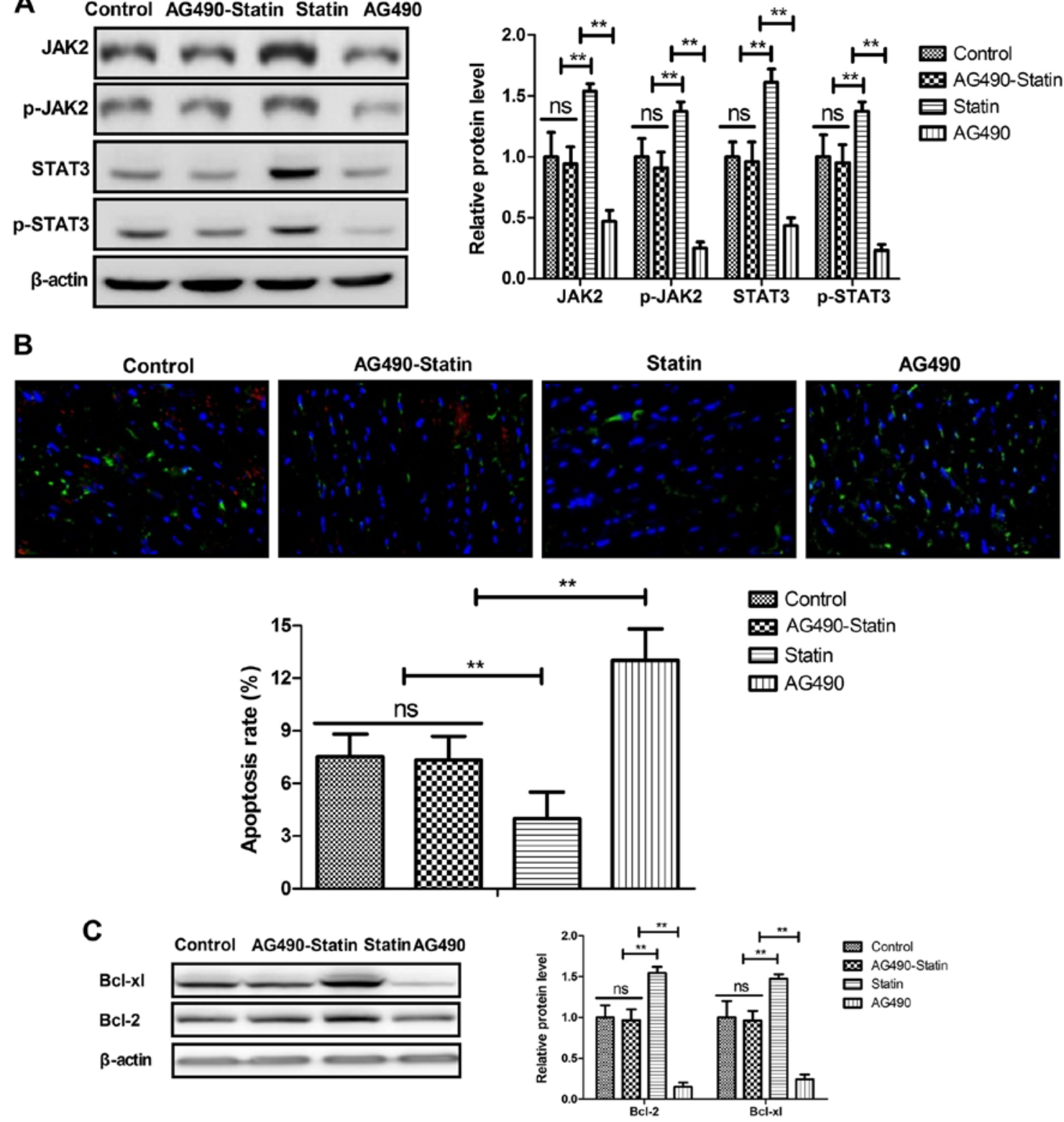

Control

× AG490-Statin

西 AG490
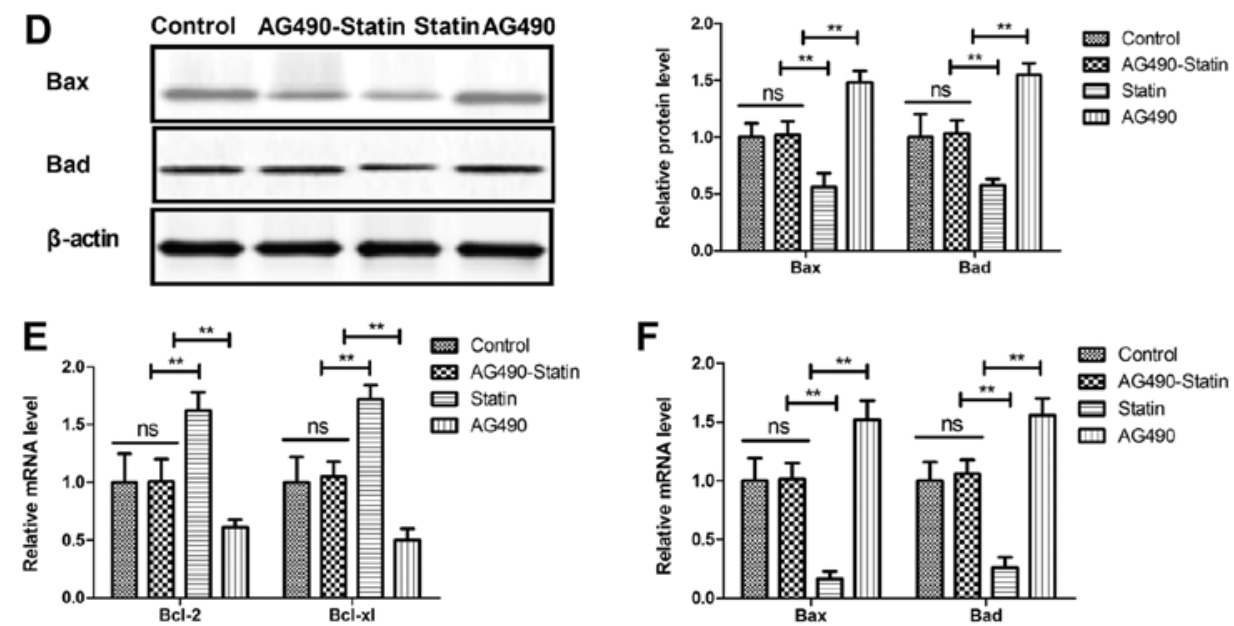

Figure 3. Statin rosuvastatin suppresses the apoptosis of HCAECs through regulation of the JAK2/STAT3 pathway. (A) JAK2 selective inhibitor AG490 decreased and abolished statin-regulated JAK2, p-JAK2, STAT3 and p-STAT3 expression in the HCAECs. (B) JAK2 selective inhibitor AG490 decreased and abolished statin-inhibited apoptosis of HCAECs (magnification, x50). (C) Effects of JAK2 selective inhibitor AG490 on statin-regulated Bcl-xl and Bcl-2 protein expression in the HCAECs. (D) Effects of JAK2 selective inhibitor AG490 on statin-regulated Bax and Bad protein expression in the HCAECs. (E) Effects of JAK2 selective inhibitor AG490 on statin-regulated Bcl-xl and Bcl-2 gene expression in the HCAECs. (F) Effects of JAK2 selective inhibitor AG490 on statin-regulated Bax and Bad gene expression in HCAECs. ${ }^{* *} \mathrm{P}<0.01$; ns, not significant; HCAEC, human coronary artery endothelial cells; JAK, Janus kinase; p-, phosphorylated; STAT, signal transducer and activator of transcription. 
A

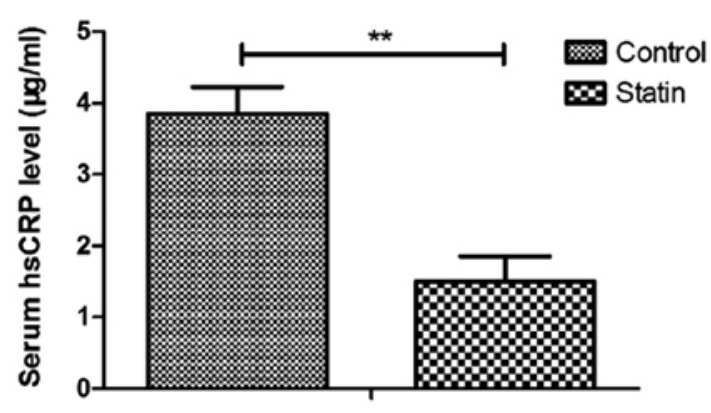

C
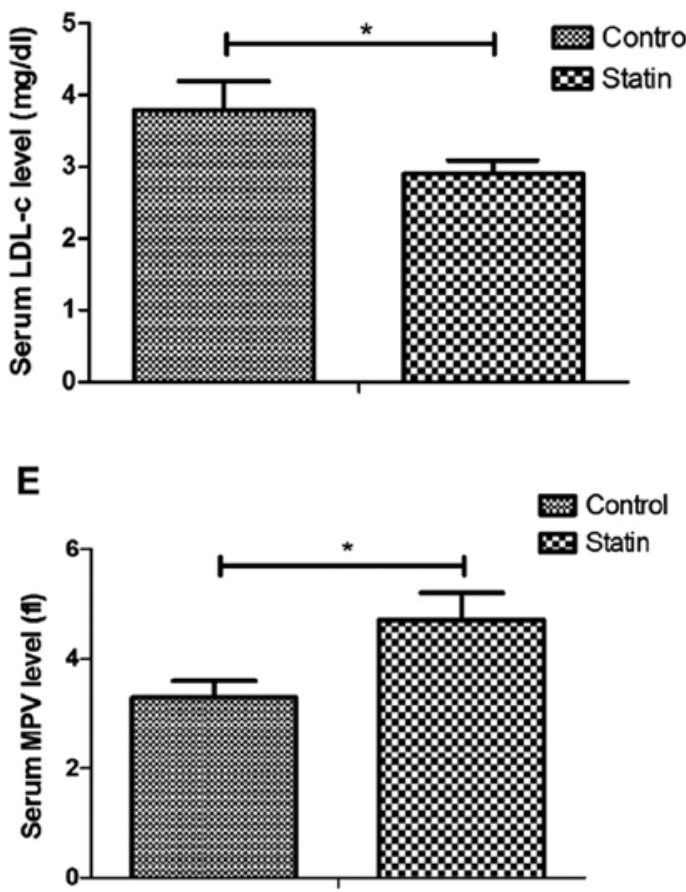

G

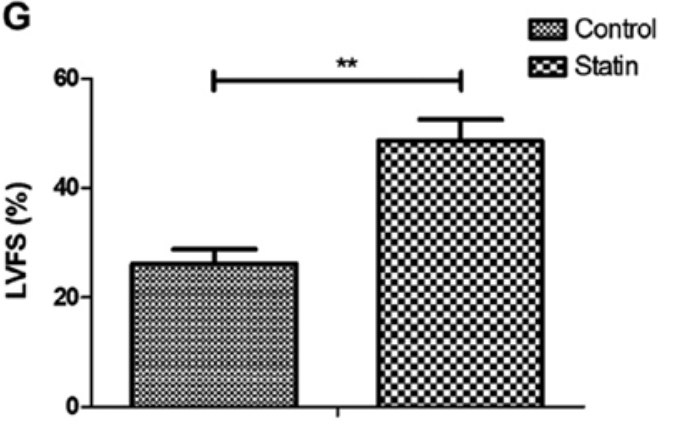

B

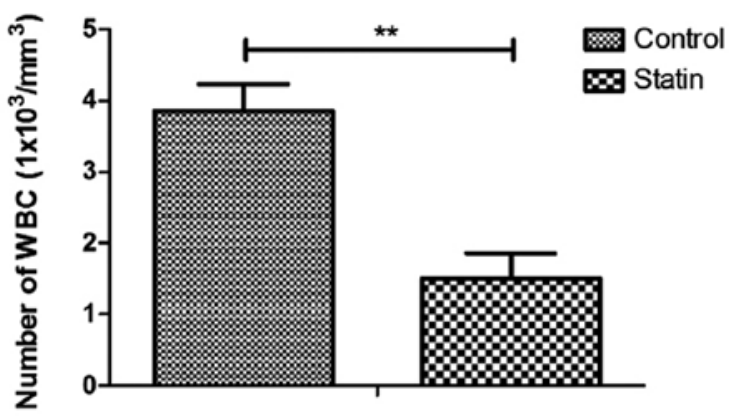

D

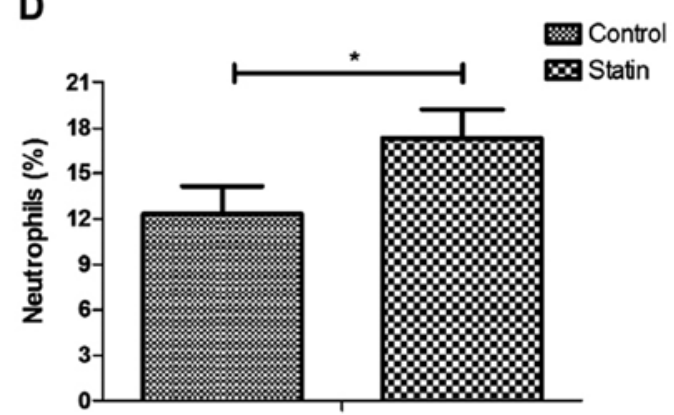

$\mathbf{F}$

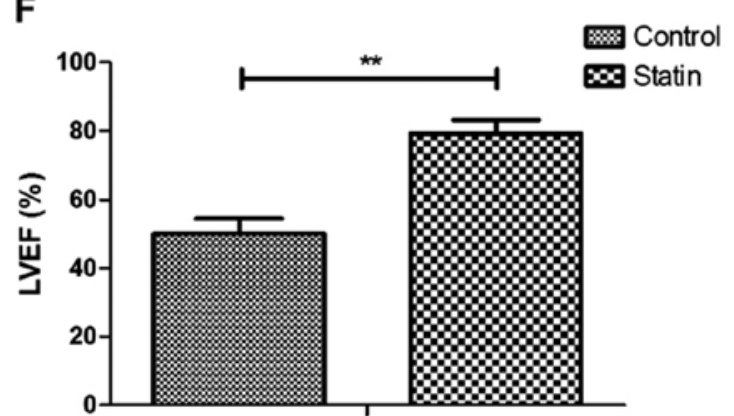

Figure 4. Effects of statin rosuvastatin on inflammatory markers and cellular parameters in a myocardial infarction rat model. Effects of statin on (A) blood hsCRP concentration, (B) number of WBCs, (C) LDL-c, (D) neutrophils, (E) MPV, (F) LVEF and (G) LVFS in myocardial infarction rat model. "P $<0.05$, ${ }^{* *} \mathrm{P}<0.01$. hsCRP, hypersensitive C-reactive protein; WBC, leucocytes; LDL-c, low-density lipoprotein cholesterol; MPV, mean platelet volume; LVEF, left ventricular ejection fraction; LVFS, left ventricular fractional shortening.

In vivo efficacy of statin for myocardial infarction. In vivo efficacy of the statin rosuvastatin was investigated in a myocardial infarction rat model. It was observed that statin treatment markedly decreased the mitochondrial ROS and the myocardial infarction areas (Fig. 6A and B). Results also indicated that rosuvastatin treatment significantly decreased thrombogenesis in the experiment rats after the 60-day treatment (Fig. 6C).
The results revealed that Bax and Bad production was also decreased by statin treatment compared with the control (Fig. 6D). Treatment with the statin significantly improved the cardiac function indicators left ventricular end-diastolic posterior wall thickness and left ventricular end-diastolic diameter (Fig. 6E) and significantly increased expression levels of JAK and STAT3 in myocardial tissue (Fig. 6F). These results 
A

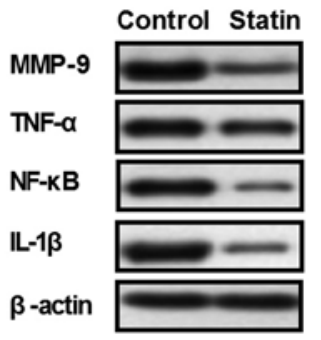

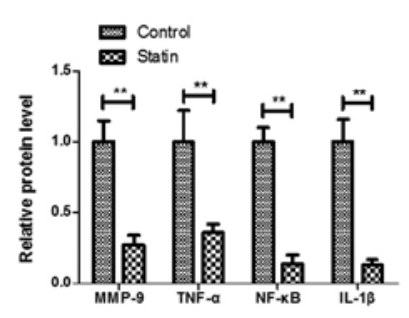

B
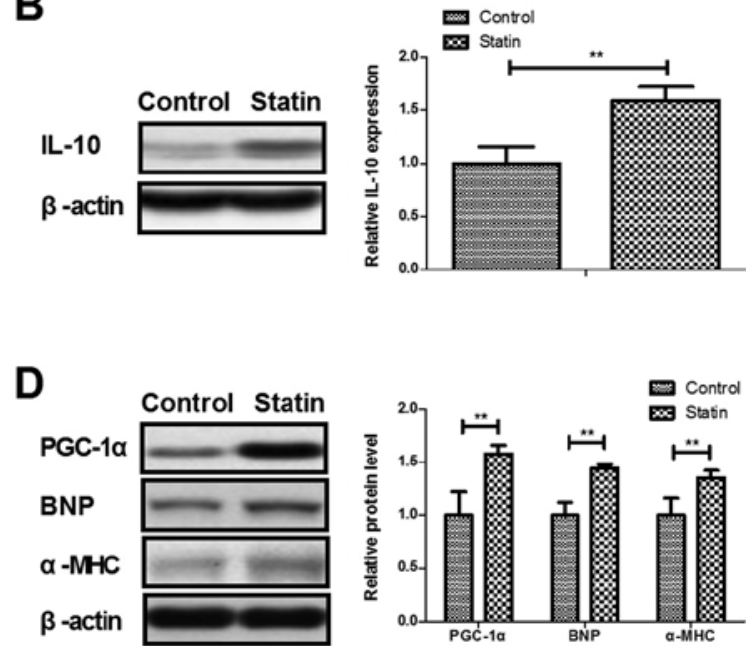

Figure 5. Expression levels of inflammatory factors, mitochondrial damage and cardiac hypertrophic failure in a myocardial infarction rat model. (A) Effects of statin rosuvastatin on the protein levels of MMP-9, TNF- $\alpha$, NF- $\mathrm{kB}$ and IL-1 $\beta$ in heart tissue. (B) Effects of statin on anti-inflammatory cytokine IL-10 in heart tissue. (C) Effects of statin on cytosolic Cytochrome c expression in heart tissue. (D) Effects of statin on PGC-1 $\alpha$, BNP and $\alpha$-MHC expression in heart tissue. ${ }^{* *} \mathrm{P}<0.01$. MMP, matrix metalloproteinase; TNF, tumor necrosis factor; NF- $\kappa \mathrm{B}$, nuclear factor $\kappa \mathrm{B}$; IL, interleukin; PGC, peroxisome proliferator-activated receptor $\gamma$ coactivator; BNP, brain natriuretic peptide; $\alpha$-MHC, $\alpha$ myosin heavy chain.

indicate that statin treatment was beneficial for the treatment of myocardial infarction.

\section{Discussion}

Prospective review and randomized clinical trials have investigated factors associated with increased coronary heart disease risk (31). Expression of apoptosis factors following coronary heart disease are increased in patients in the clinic (32). Data in a systematic review and meta-analysis indicate the therapeutic effects of perioperative statins on death, myocardial infarction, atrial fibrillation and length of stay (33). The present study first investigated the beneficial effects of statin rosuvastatin for coronary artery endothelial cells induced by $\mathrm{CoCl}_{2}$ both in vitro and in vivo. Statin treatment decreased serum level of hsCRP, WBCs, LDL-c, but increased serum level of neutrophils, MPV, LVEF and LVFS compared with control treatment in a myocardial infarction rat model. Statin significantly improved viability of HCAECs induced by $\mathrm{CoCl}_{2}$ and improved inflammation, mitochondrial damage and cardiac hypertrophic failure. Statin suppressed apoptosis of HCAECs by increasing JAK2/STAT3 signaling pathway-related proteins.

A previous study evaluated the kinetics of cardiomyocyte apoptosis in patients undergoing primary percutaneous coronary intervention and thrombolytic therapy (34). Statin administration was found to mitigate cellular inflammatory response following ST-elevation myocardial infarction in a total of 404 patients (35). The present study reported that statin treatment presented anti-apoptotic effects on HCAECs induced by $\mathrm{CoCl}_{2}$. In addition, Bax deficiency was previously found to reduce infarct size and improve long-term function following myocardial infarction (36). Activation of the Bad apoptotic pathway and the PI3K/Akt survival pathway has been observed following myocardial infarction (37). The present study showed that rosuvastatin administration significantly decreased Bax and Bad expression levels in HCAECs.
Furthermore, Bcl-2 upregulation contributed to anti-apoptosis of cardiomyocytes in rats with myocardial infarction injury (38). Effects of statin on the anti-apoptosis of HCAECs and the increasing expression of Bcl-2 were identified in rats with myocardial infarction injury.

A previous study indicated that the role of JAK2 plays an important role in premature myocardial infarction, in support of the revised World Health Organization diagnostic criteria for essential thrombocythemia (39). The cardiac-specific ablation of the STAT3 gene in the subacute phase of myocardial infarction exacerbates cardiac remodeling (40). Notably, activation of the JAK2/STAT3 pathway protects myocardium against ischemia/reperfusion injury (41). The present study reported that rosuvastatin significantly suppressed apoptosis of HCAECs through regulation of the JAK2/STAT3 pathway. A previous study noted that myocardial caspase-3 activation promotes calpain-induced septic apoptosis (42). Another study indicated that decreasing cleaved-caspase-9 expression inhibits myocardial cell apoptosis during myocardial ischemia-reperfusion injury in rats (43). In the present study, it was observed that statin treatment decreased caspase-3 and caspase-9 expression in HCAECs induced by $\mathrm{CoCl}_{2}$. However, HCAECs should be isolated from the myocardial infarction rat model for detection in future studies. The present study also suggested that statin treatment contributes to improvements in myocardial infarction via decreasing mitochondrial ROS and the myocardial infarction areas. Statin treatment significantly decreased thrombogenesis in the experimental rats following the 60-day treatment, decreased Bax and Bad production and increased the expression levels of JAK and STAT3 in myocardial tissue.

The novelty of the present study was that its data demonstrated that the statin rosuvastatin inhibited the apoptosis of HCAECs through regulation of JAK2/STAT3. However, there were several limitations in the present study. First, the data of cells without $\mathrm{CoCl}_{2}$ treatment were not collected in the in vitro experiments. Second, data in a sham group was not investigated in in vivo experiments. Third, the present 
A

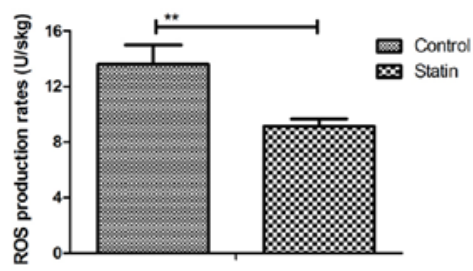

B
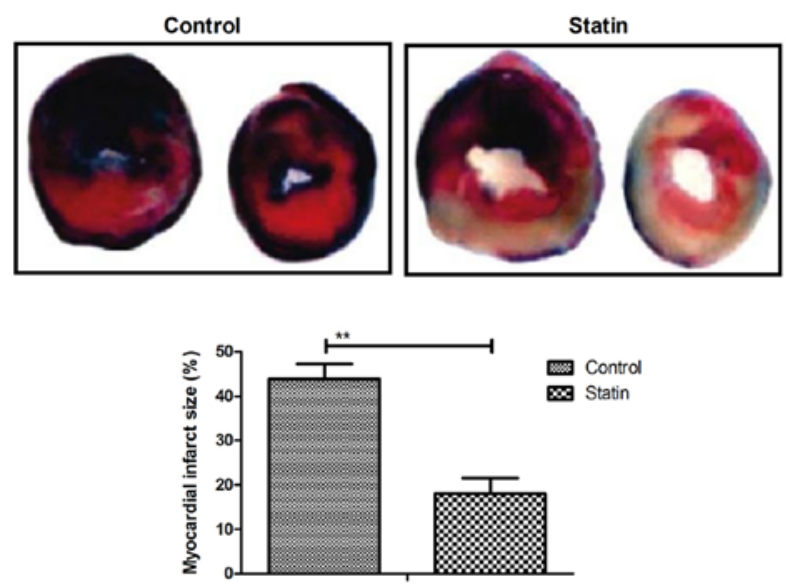

E
C

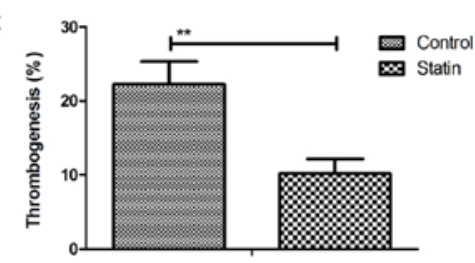

D
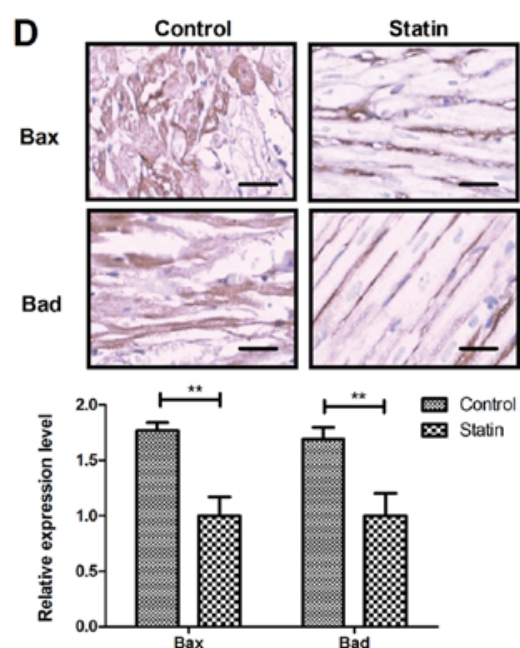

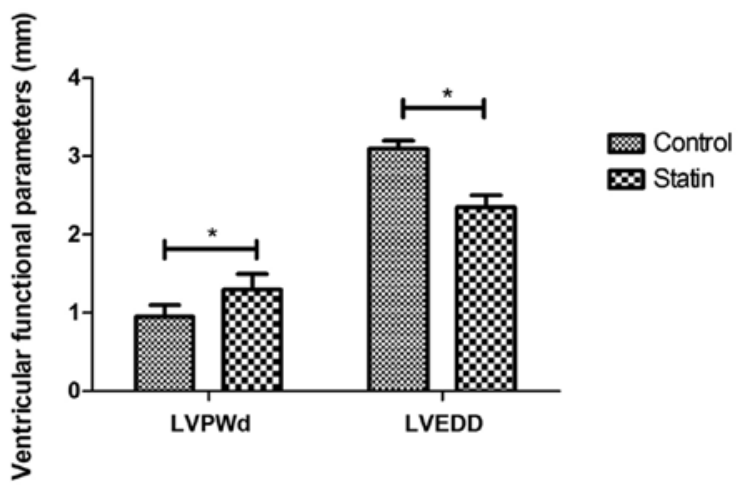

$\mathbf{F}$
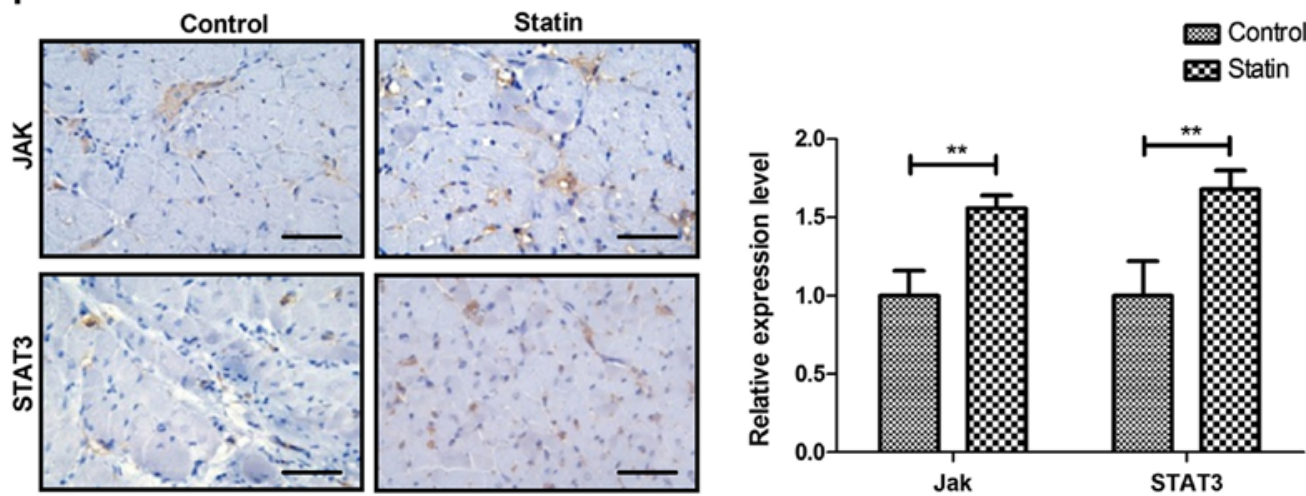

Figure 6. In vivo efficacy of statin rosuvastatin on myocardial infarction. (A) Statin treatment markedly decreased the mitochondrial ROS in a myocardial infarction rat model. (B) Statin treatment decreased myocardial infarction area in the experimental rats. (magnification, x50). (C) Statin treatment decreased thrombogenesis in the experimental rats after the 60-day treatment. (D) Statin treatment decreased Bax and Bad production in the experimental rats after the 60-day treatment. (E) Statin improved the cardiac function indicators LVPWd and LVEDD. (F) Statin increased expression level of JAK and STAT3 in myocardial tissue. Scale bar, $50 \mu \mathrm{m} .{ }^{*} \mathrm{P}<0.05,{ }^{* *} \mathrm{P}<0.01$. ROS, reactive oxygen species; LVPWd, left ventricular end-diastolic posterior wall thickness; LVEDD, left ventricular end-diastolic diameter; JAK, Janus kinase; STAT, signal transducer and activator of transcription.

study only analyzed the associations between statin and the JAK2/STAT3 signaling pathway in HCAECs. Fourth, HCAECs were not isolated from the myocardial infarction rats. Therefore, more experiments should investigate the effect of statins on HCAECs isolated from myocardial infarction rats in future studies. In addition, the effect of statins on cardiac tissue cannot directly demonstrate the anti-apoptotic effect of statins on HCAECs. 
In conclusion, the present study indicated that the cardioprotective effects of statin are associated with the upregulation of JAK2/STAT3, which further decreased the apoptosis of HCAECs. It was found that rosuvastatin significantly improved mitochondrial ROS and the myocardial infarction areas in experiment rats following the 60-day treatment. However, further studies of the JAK2/STAT3 signaling pathway should be further investigated in the progression of myocardial infarction.

\section{Acknowledgements}

Not applicable.

\section{Funding}

No funding was received.

\section{Availability of data and materials}

The datasets used and/or analyzed during the current study are available from the corresponding author on reasonable request.

\section{Authors' contributions}

KW and BL performed the experiments. YX, NX and ML acquired, analyzed and interpreted the data. GG designed the study and drafted the manuscript. All authors read and approved the final manuscript.

\section{Ethics approval and consent to participate}

The present study was approved by the Ethics Committee of AnZhen Hospital of Beijing (Beijing, China).

\section{Patient consent for publication}

Not applicable.

\section{Competing interests}

The authors declare that they have no competing interests.

\section{References}

1. Fan FF, Xu Q, Sun Q, Zhao SJ, Wang P and Guo XR: Assessment of the reporting quality of randomized controlled trials on treatment of coronary heart disease with traditional Chinese medicine from the Chinese journal of integrated traditional and Western medicine: A systematic review. PLoS One 9: e86360, 2014.

2. Doyle F, Rohde D, Rutkowska A, Morgan K, Cousins G and McGee H: Systematic review and meta-analysis of the impact of depression on subsequent smoking cessation in patients with coronary heart disease: 1990 to 2013. Psychosom Med 76: 44-57, 2014.

3. Tully PJ and Baumeister H: Collaborative care for the treatment of comorbid depression and coronary heart disease: A systematic review and meta-analysis protocol. Syst Rev 3: 127, 2014.

4. Schwingshackl L and Hoffmann G: Dietary fatty acids in the secondary prevention of coronary heart disease: A systematic review, meta-analysis and meta-regression. BMJ Open 4: e004487, 2014

5. Tully PJ, Cosh SM and Baumeister $\mathrm{H}$ : The anxious heart in whose mind? A systematic review and meta-regression of factors associated with anxiety disorder diagnosis, treatment and morbidity risk in coronary heart disease. J Psychosom Res 77: 439-448, 2014
6. Li SM, Xu H and Chen KJ: Integrative medicine on coronary heart disease: Annual academic review 2013. Zhongguo Zhong Xi Yi Jie He Za Zhi 34: 1029-1034, 2014 (In Chinese).

7. Ray IB, Menezes AR, Malur P, Hiltbold AE, Reilly JP and Lavie CJ: Meditation and coronary heart disease: A review of the current clinical evidence. Ochsner J 14: 696-703, 2014.

8. Niermann C, Gorressen S, Klier M, Gowert NS, Billuart P, Kelm M, Merx MW and Elvers M: Oligophrenin1 protects mice against myocardial ischemia and reperfusion injury by modulating inflammation and myocardial apoptosis. Cell Signal 28: 967-978, 2016

9. Guo CX, Jiang X, Zeng XJ, Wang HX, Li HH, Du FH and Chen BX: Soluble receptor for advanced glycation end-products protects against ischemia/reperfusion-induced myocardial apoptosis via regulating the ubiquitin proteasome system. Free Radic Biol Med 94: 17-26, 2016.

10. Shi ZY, Liu Y, Dong L, Zhang B, Zhao M, Liu WX, Zhang X and Yin XH: Cortistatin improves cardiac function after acute myocardial infarction in rats by suppressing myocardial apoptosis and endoplasmic reticulum stress. J Cardiovasc Pharmacol Ther 22: 83-93, 2016.

11. Nishikido T, Oyama J, Shiraki A, Komoda H and Node K: Deletion of Apoptosis Inhibitor of Macrophage (AIM)/CD5L attenuates the inflammatory response and infarct size in acute myocardial infarction. J Am Heart Assoc 5: e002863, 2016.

12. Kvan E, Pettersen KI, Landmark K and Reikvam A: Treatment with statins after acute myocardial infarction in patients $>$ or $=80$ years: Underuse despite general acceptance of drug therapy for secondary prevention. Pharmacoepidemiol Drug Saf 15: 261-267, 2006.

13. Zhou Z, Rahme E, Abrahamowicz M, Tu JV, Eisenberg MJ, Humphries K, Austin PC and Pilote L: Effectiveness of statins for secondary prevention in elderly patients after acute myocardial infarction: An evaluation of class effect. CMAJ 172: 1187-1194, 2005.

14. Iwakura K, Ito H, Kawano S, Okamura A, Kurotobi T, Date M, Inoue $\mathrm{K}$ and Fujii K: Chronic pre-treatment of statins is associated with the reduction of the no-reflow phenomenon in the patients with reperfused acute myocardial infarction. Eur Heart J 27: 534-539, 2006.

15. Matetzky S, Fefer P, Shenkman B, Shechter M, Novikov I, Savion N, Varon D and Hod H: Statins have an early antiplatelet effect in patients with acute myocardial infarction. Platelets 22 : 103-110, 2011.

16. Lewinter C, Bland JM, Crouch S, Cleland JG, Doherty P, LeWinter MM, Køber L, Hall AS and Gale CP: Impact of aspirin and statins on long-term survival in patients hospitalized with acute myocardial infarction complicated by heart failure: An analysis of 1706 patients. Eur J Heart Fail 16: 95-102, 2014.

17. Verrier RL: Statins protect against arrhythmogenic calcium alternans in the post-myocardial infarction diabetic heart: Pleiotropy on steroids. Heart Rhythm 14: 1417-1418, 2017.

18. Yamac AH and Kilic U: Effect of statins on sirtuin 1 and endothelial nitric oxide synthase expression in young patients with a history of premature myocardial infarction. Turk Kardiyol Dern Ars 46: 205-215, 2018.

19. Xu H, Yang YJ, Qian HY, Tang YD, Wang H and Zhang Q: Rosuvastatin treatment activates JAK-STAT pathway and increases efficacy of allogeneic mesenchymal stem cell transplantation in infarcted hearts. Circ J 75: 1476-1485, 2011.

20. Rajtik T, Carnicka S, Szobi A, Mesárošová L, Mát’uš M, Švec P, Ravingerová T and Adameová A: Pleiotropic effects of simvastatin are associated with mitigation of apoptotic component of cell death upon lethal myocardial reperfusion-induced injury. Physiol Res 61 (Suppl 2): S33-S41, 2012.

21. Qiu R, Cai A, Dong Y, Zhou Y, Yu D, Huang Y, Zheng D, Rao S, Feng Y and Mai W: SDF-1 $\alpha$ upregulation by atorvastatin in rats with acute myocardial infarction via nitric oxide production confers anti-inflammatory and anti-apoptotic effects. J Biomed Sci 19: 99, 2012.

22. Han L, Zhang X and Qian Y: Propofol protects human cardiac AC16 cells from $\mathrm{CoCl} 2$-induced hypoxic injury. Zhong Nan Da Xue Xue Bao Yi Xue Ban 44: 307-314, 2019 (In Chinese).

23. Radecke CE, Warrick AE, Singh GD, Rogers JH, Simon SI and Armstrong EJ: Coronary artery endothelial cells and microparticles increase expression of VCAM-1 in myocardial infarction. Thromb Haemost 113: 605-616, 2015.

24. Xiao S, Wang $\mathrm{J}$ and Xiao N: MicroRNAs as noninvasive biomarkers in bladder cancer detection: A diagnostic meta-analysis based on qRT-PCR data. Int J Biol Markers 31: e276-e285, 2016. 
25. Livak KJ and Schmittgen TD: Analysis of relative gene expression data using real-time quantitative PCR and the 2(-Delta Delta C(T)) method. Methods 25: 402-408, 2001.

26. Naganuma Y,Ichii O, Otsuka S, Hashimoto Y and Kon Y: Analysis of TdT-mediated dUTP nick end labeling (TUNEL)-positive cells associated with cardiac myogenesis in mouse embryo. J Vet Med Sci 75: 283-290, 2013.

27. Zhang R, Kang X, Wang Y, Wang F, Yu P, Shen J and Fu L: Effects of carvedilol on ventricular remodeling and the expression of $\beta 3$-adrenergic receptor in a diabetic rat model subjected myocardial infarction. Int J Cardiol 222: 178-184, 2016.

28. Bagno LL, Carvalho D, Mesquita F, Louzada RA, Andrade B, Kasai-Brunswick TH, Lago VM, Suhet G, Cipitelli D, Werneck-de-Castro JP and Campos-de-Carvalho AC: Sustained IGF-1 secretion by adipose-derived stem cells improves infarcted heart function. Cell Transplant 25: 1609-1622, 2016.

29. Paradiso A, Caretto S, Leone A, Bove A, Nisi R and De Gara L: ROS production and scavenging under anoxia and re-oxygenation in arabidopsis cells: A balance between redox signaling and impairment. Front Plant Sci 7: 1803, 2016.

30. Dirani M,Nasreddine W, Abdulla F and Beydoun A: Seizure control and improvement of neurological dysfunction in Lafora disease with perampanel. Epilepsy Behav Case Rep 2: 164-166, 2014.

31. Hashemian M, Poustchi H, Mohammadi-Nasrabadi F and Hekmatdoost A: Systematic review of zinc biochemical indicators and risk of coronary heart disease. ARYA Atheroscler 11: 357-365, 2015.

32. Liu LL, Lin LR, Lu CX, Fu JG, Chao PL, Jin HW, Zhang ZY and Yang TC: Expression of inflammatory and apoptosis factors following coronary stent implantation in coronary heart disease patients. Int Immunopharmacol 11: 1850-1854, 2011.

33. Chopra V, Wesorick DH, Sussman JB, Greene T, Rogers M, Froehlich JB, Eagle KA and Saint S: Effect of perioperative statins on death, myocardial infarction, atrial fibrillation, and length of stay: A systematic review and meta-analysis. Arch Surg 147: 181-189, 2012

34. Gultekin N, Bulut G, Kucukates E, Yildiz A, Kocas C and Bulut L: Apoptosis kinetics at reperfusion period in patients with acute ST-Segment Elevation Myocardial Infarction undergoing primary percutaneous coronary intervention and treated with thrombolytic therapy. J Pak Med Assoc 66: 808-814, 2016.

35. Pourafkari L, Visnjevac O, Ghaffari S and Nader ND: Statin drugs mitigate cellular inflammatory response after ST elevation myocardial infarction, but do not affect in-hospital mortality. J Cardiovasc Thorac Res 8: 34-39, 2016.
36. Hochhauser E, Cheporko Y, Yasovich N, Pinchas L, Offen D, Barhum Y, Pannet H, Tobar A, Vidne BA and Birk E: Bax deficiency reduces infarct size and improves long-term function after myocardial infarction. Cell Biochem Biophys 47: 11-20, 2007.

37. Li T, Kilic A, Wei X, Wu C, Schwartzbauer G, Yankey GK, DeFilippi C, Bond M, Wu ZJ and Griffith BP: Regional imbalanced activation of the calcineurin/BAD apoptotic pathway and the PI3K/Akt survival pathway after myocardial infarction. Int J Cardiol 166: 158-165, 2013.

38. Lv FH, Yin HL, He YQ, Wu HM, Kong J, Chai XY and Zhang SR Effects of curcumin on the apoptosis of cardiomyocytes and the expression of NF- $\kappa \mathrm{B}$, PPAR $-\gamma$ and Bcl-2 in rats with myocardial infarction injury. Exp Ther Med 12: 3877-3884, 2016.

39. Mercier E, Cochery-Nouvellon E, Lavigne G, Bertinchant JP and Gris JC: In support of the revised World Health Organization diagnostic criteria for essential thrombocythemia: JAK2 V617F and premature myocardial infarction. J Thromb Haemost 6: 206-207, 2008

40. Enomoto D, Obana M, Miyawaki A, Maeda M, Nakayama H and Fujio Y: Cardiac-specific ablation of the STAT3 gene in the subacute phase of myocardial infarction exacerbated cardiac remodeling. Am J Physiol Heart Circ Physiol 309: H471-H480, 2015.

41. Wu J, Yu J, Xie P, Maimaitili Y, Wang J, Yang L, Ma H, Zhang X, Yang Y and Zheng H: Sevoflurane postconditioning protects the myocardium against ischemia/reperfusion injury via activation of the JAK2-STAT3 pathway. PeerJ 5: e3196, 2017.

42. Luo R, Chen X, Ma H, Yao C, Liu M, Tao J and Li X: Myocardial caspase- 3 and NF- $\kappa B$ activation promotes calpain-induced septic apoptosis: The role of Akt/eNOS/NO pathway. Life Sci 222: 195-202, 2019.

43. Zhao Q, Cui Z, Zheng Y, Li Q, Xu C, Sheng X, Tao M and Xu H: Fenofibrate protects against acute myocardial I/R injury in rat by suppressing mitochondrial apoptosis as decreasing cleaved caspase-9 activation. Cancer Biomark 19: 455-463, 2017.

This work is licensed under a Creative Commons Attribution-NonCommercial-NoDerivatives 4.0 International (CC BY-NC-ND 4.0) License. 